\title{
The Effect of Pulsed Nanosecond Laser Irradiation on the Corrosion Resistance of $\mathrm{Mg}-\mathrm{Al}-\mathrm{Zn}$ Magnesium Alloy
}

\author{
S. A. Bozhko ${ }^{a, *}$, S. S. Manokhin ${ }^{b, * *}$, A. Yu. Tokmacheva-Kolobova ${ }^{b, * * *}$, \\ Yu. Yu. Karlagina ${ }^{c, * * * *}$, and A. E. Ligachev ${ }^{d, * * * * *}$ \\ ${ }^{a}$ Belgorod State National Research University, Belgorod, 308015 Russia \\ ${ }^{b}$ Institute of Problems of Chemical Physics, Russian Academy of Sciences, Chernogolovka, Moscow oblast, 142432 Russia \\ ${ }^{c}$ ITMO University, St. Petersburg, 197101 Russia \\ ${ }^{d}$ Prokhorov General Physics Institute, Russian Academy of Sciences, Moscow, 119991 Russia \\ *e-mail: sambusa@inbox.ru \\ **e-mail:manohin@bk.ru \\ ***e-mail: anastasiia.misis@gmail.ru \\ ****e-mail:julia.karl@mail.ru \\ *****e-mail: carbin@yandex.ru \\ Received May 30, 2019; revised September 30, 2019; accepted October 24, 2019
}

\begin{abstract}
The corrosion resistance of $\mathrm{Mg}-\mathrm{Al}-\mathrm{Zn}$ magnesium alloy with coarse-grained and ultrafinegrained structures before and after the treatment of the surface of the alloy with pulsed nanosecond laser irradiation is studied. It is found that this treatment significantly increases the resistance of the alloy to its dissolution in a $0.9 \% \mathrm{NaCl}$ saline only under the condition of preliminary formation of a uniform ultrafine-grained structure in the bulk of the sample. The observed effect can be considered as a promising method for the treatment of the surface of medical devices made of biodegradable magnesium alloys.
\end{abstract}

Keywords: pulsed nanosecond laser irradiation, magnesium alloys, corrosion resistance

DOI: $10.1134 /$ S2075113320030077

\section{INTRODUCTION}

In the last decade, magnesium and its alloys have been actively studied for the purpose of their application in medicine. The combination of its useful properties such as low density $\left(1.74 \mathrm{~g} / \mathrm{cm}^{3}\right.$, which is close to the bone density), high strength-to-weight ratio, and capacity of magnesium for complete dissolution in the body with no harm to the health of the human body makes it possible to use magnesium alloys as a base for the fabrication of medical biodegradable implants [1-3].

The main disadvantage of magnesium as a material for the fabrication of implants soluble in the body is its low strength and poor capacity of the alloys based on it for strengthening without critical loss of its plasticity, which does not allow subjecting products based on magnesium alloys to severe deformation operations such as molding, bending, and shrinkage. Here, the most widely used method for increasing the strength of magnesium is its alloying and thermal treatment. However, it is very challenging to achieve the required gain in strength by means of alloying without a decrease in the important properties such as corrosion resistance and plasticity [4, 5]. Because of this, implants lose their performance characteristics before the expiration of their required service life. The application of the various modes of thermal treatment of magnesium alloys which have been developed so far somewhat increases the corrosion resistance of the material of an implant but substantially decreases its strength characteristics [4]. Therefore, no significant progress in the formation of the optimum balance between the mechanical and corrosion properties of magnesium alloys has been achieved thus far despite individual successful attempts to use some versions of doped alloys based on magnesium which are applied in medical practice [6-10].

It is also known that the processes of corrosion of magnesium alloys are affected by the structural phase state of both their near-surface layers (which is associated with the precipitation of the particles of secondary phases that promote the development of galvanic corrosion in the first place) and inner bulk of the material (the grain size and uniformity of the structure affect the uniformity of the passivating film being formed, which can be prematurely destroyed because of the appearance of surface tensions) [11]. Therefore, it is necessary to search for new ways of increasing the corrosion resistance of magnesium implants during 
the first days of their operation in vivo by means of formation of the optimum parameters of the structural phase state not only in the bulk of magnesium alloys but also on their surface.

A promising method for improving the physicochemical properties of medical titanium, magnesium, and other alloys is thermomechanical treatment that includes helical and flat-and-edge rolling of threedimensional blanks for the purpose of formation of a uniform grain-subgrain structure with the uniform distribution of the phase inclusions (if any) throughout the entire bulk of the material $[12,13]$ and surface treatment. The combination of these two methods of action on the structural phase composition of a material makes it possible to change the properties of the material not only in its bulk but also in the near-surface layer (including the topography of the surface). The resistance of an alloy to dissolution in an aggressive environment can be increased using such a combined treatment, which in turn should provide the preservation of the performance characteristics of the material of an implant under the conditions of action of the internal environment of the human body.

As for the methods of thermomechanical treatment, it was experimentally shown earlier that the formation of a high-strength ultrafine-grained state with a uniform structure can be achieved in a magnesium alloy of the $\mathrm{Mg}-\mathrm{Al}-\mathrm{Zn}$ system by means of lengthwise flat-and-edge rolling [12]. However, the formation of such structures in doped magnesium alloys is accompanied by the ample precipitation of the secondary phase in the form of intermetallic particles, which promotes the development of galvanic corrosion owing to the formation of galvanic pairs between the grains of the matrix and particles of the $\beta$ phase of $\mathrm{Mg}_{x} \mathrm{Al}_{y}$ and leads to a decrease in the corrosion resistance of the alloy. It is possible to get rid of these precipitates by means of the action of pulsed laser radiation on the magnesium alloy. In this case, only the structure and phase composition of the near-surface layer of the alloy under treatment should be changed, and the state of the material in the bulk remains intact [14-18].

The aim of this work is the investigation of the influence of pulsed nanosecond laser treatment on the corrosion properties of the surface of a magnesium alloy in different structural states upon long-term exposures of the alloy in a solution mimicking the physiological environment.

\section{EXPERIMENTAL}

A wrought magnesium alloy of the MA5 brand ((7.8-9.2)Al, (0.15-0.5) Mn, (0.2-0.8) Zn, GOST (State Standard) 14957) in the coarse-grained (CG) recrystallized and ultrafine-grained (UFG) states was chosen for the studies. The UFG state was formed by the technology of thermomechanical treatment using flat-and-edge rolling at an elevated temperature [19].
The average mode grain size in the UFG samples was $1 \mu \mathrm{m}$. The recrystallized state was obtained by annealing the samples of the magnesium alloy in the UFG state in air at $350^{\circ} \mathrm{C}$ for $2.5 \mathrm{~h}$. The average grain size after the annealing was $10 \mu \mathrm{m}$.

The surface of the magnesium alloys was modified with pulsed nanosecond laser irradiation (NLI) with the use of an ytterbium fiber laser with the wavelength of $1.06 \mu \mathrm{m}$ and pulse duration of $100 \mathrm{~ns}$ [20].

To determine the corrosion resistance, the samples were immersed in a $0.9 \%$ solution of sodium chloride and exposed in it for 25 days at $37^{\circ} \mathrm{C}$. Upon the expiry of different time periods, the samples were rinsed in distilled water, dried in air, and weighed. After this, the samples were again immersed in the solution until the next removal. The dependences of the relative change in the weight of the samples at each immersion interval on the time of action of the corrosive environment were constructed on the basis of the results of weighing.

The structure was studied using Quanta 600 FEG and Quanta NOVA NanoSEM 450 scanning electron microscopes with field electron emission and a scanning transmission microscopy (STEM) detector.

\section{RESULTS AND DISCUSSION}

MA5 magnesium alloy with a pronounced twophase structure based on a matrix and precipitations of the $\beta$ phase of $\mathrm{Mg}_{17} \mathrm{Al}_{12}$ is one of the least resistant to galvanic corrosion in its group of alloys [21]. The formation of large precipitations of the intermetallic of the $\beta$ phase leads to the premature destruction of the protective oxide film being formed on the surface of the alloy [22], which makes the formation of the UFG state with a uniform grain size and distribution of finely disperse precipitations of the $\beta$ phase throughout the bulk the most preferable for the further treatment of the alloy by laser radiation.

The structure of the alloy in the initial state consists of large grains of the matrix with nonuniform precipitations of the particles of the $\beta$-phase intermetallic with a round or lamellar shape predominantly located on the grain boundaries (Fig. 1a). As a result of the treatment of a CG magnesium alloy at elevated temperatures [19], an equilibrium UFG structure with an average mode grain size of the alpha-matrix of $1 \mu \mathrm{m}$ and uniformly distributed precipitations of the intermetallic particles with the size close to that of the grains apart from rare relatively large (no more than $5 \mu \mathrm{m}$ ) particles is formed in it (Fig. 1b). After the thermomechanical treatment, the particles of the $\beta$ phase hardly accumulate along the grain boundaries, and they can be divided to two groups, namely, microprecipitations of the $\beta$ phase with a size of 1 to $2.5 \mu \mathrm{m}$ and nanoprecipitations of the $\beta$ phase with a size of $\sim 100 \mathrm{~nm}$ (Fig. 1c).

A developed relief with a nonperiodic structure that consists of individual globular buildups with a size of 10 to $30 \mu \mathrm{m}$ is formed on the surface of the magne- 

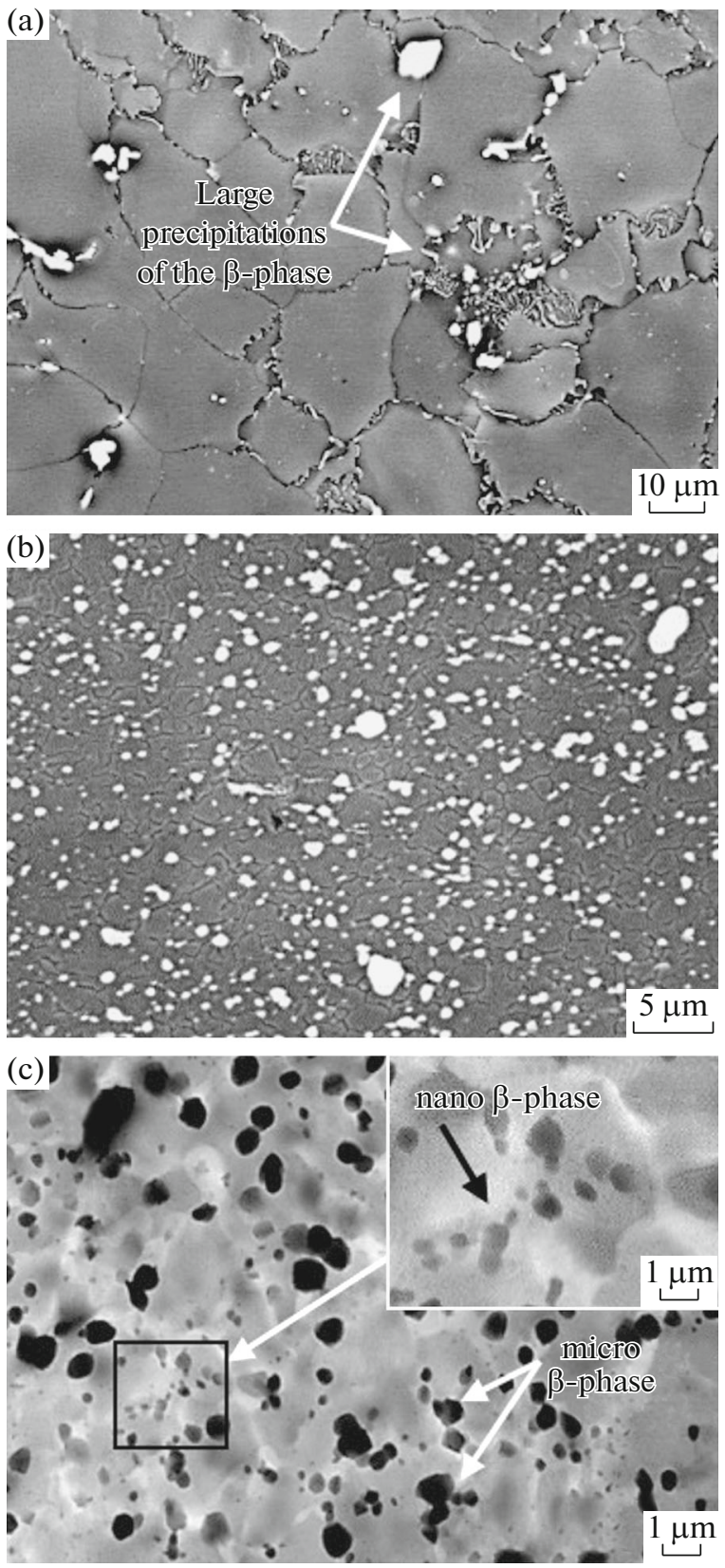

Fig. 1. Structure of MA5 magnesium alloy: (a) CG state (SEM); (b) UFG state, overview (SEM); (c) UFG state, detailed image; the inset shows a magnified region of the precipitations of the nanoparticles of the $\beta$ phase (STEM).

sium alloy under the action of laser radiation (Figs. 2a, $2 b)$. Such a relief does not depend on the initial structure of the support of the sample. It should also be noted that visible precipitations of intermetallic particles are absent on the surface of the alloy, which is most likely associated with the disintegration of the $\beta$ phase in the process of treatment of the magnesium alloy by laser radiation. The probable reason for their absence is the short time of action of laser radiation on the near-surface layer, as a result of which the inter-
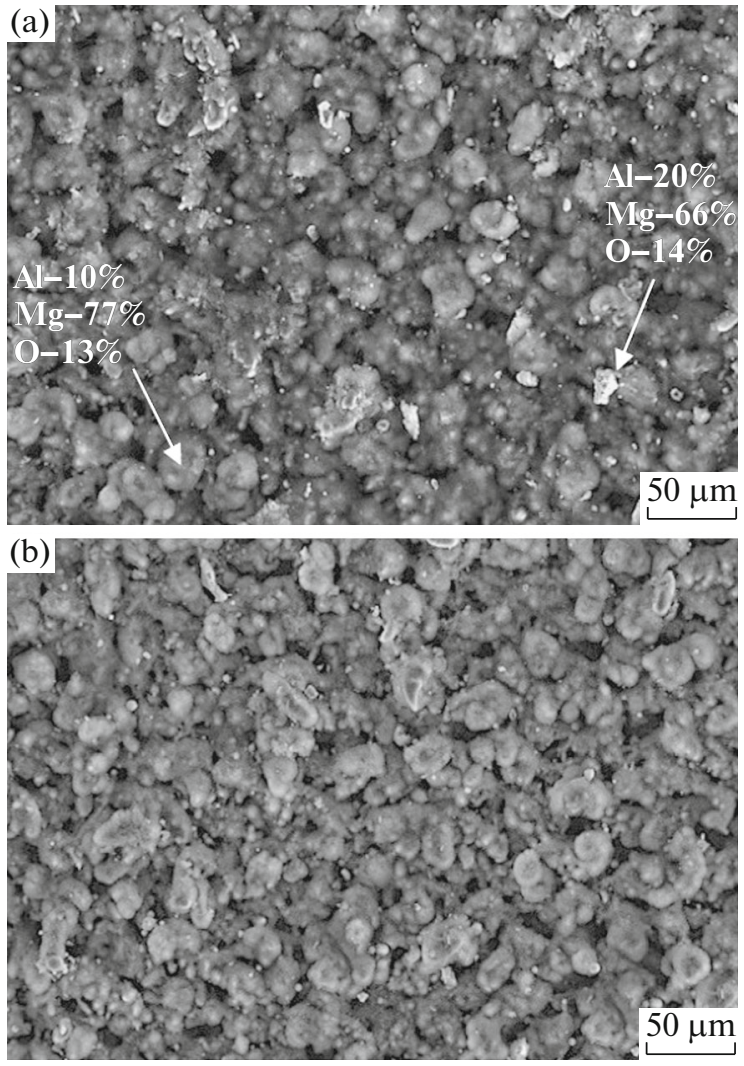

Fig. 2. SEM image of the surface of MA5 magnesium alloy in the (a) CG and (b) UFG states after pulsed NLI.

metallic particles have no time to repeatedly precipitate. Here, as was shown by energy dispersive analysis, there were regions with increased and decreased concentrations of aluminum in the CG sample (Fig. 2a, indicated by arrows), which may be associated with the presence of large particles of the $\beta$ phase in this sample and their nonuniform distribution in the matrix. Therefore, NLI promotes the formation of a modified near-surface layer free from the precipitations of the secondary phase, while uniform distribution of aluminum which prevents the development of galvanic corrosions is also observed in the case of irradiation of a sample with the UFG structure.

The studies of the dissolution of a magnesium alloy with the CG and UFG structures in a solution of $0.9 \%$ $\mathrm{NaCl}$ as a result of corrosion made it possible to find the following (Fig. 3). Active dissolution of the alloy is observed at the initial stages of exposure in the corrosive environment for a sample with the UFG structure owing to the presence of particles of the secondary phase of the intermetallic $\mathrm{Mg}_{x} \mathrm{Al}_{y}$ formed as a result of the thermomechanical treatment on the surface. The rate of corrosion decreases after 3 days of exposure in the corrosive environment and reaches the minimum value after 15 days of exposure owing to the formation of a passivating film on the surface of the magnesium 


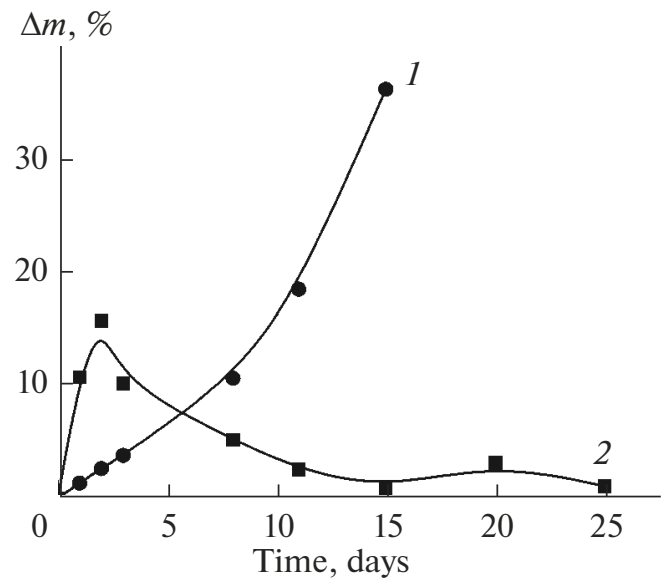

Fig. 3. Dependence of the relative decline in the weight of the samples of MA5 alloy in the (1) CG and (2) UFG states on the time of exposure in a $0.9 \%$ solution of $\mathrm{NaCl}$.

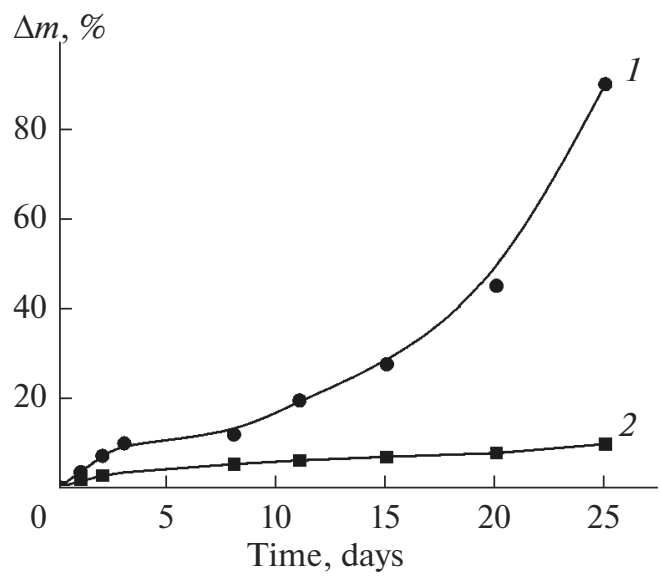

Fig. 4. Dependence of the relative change in the weight of the samples of MA5 alloy in the (1) CG and (2) UFG states after NLI on the time of exposure in a $0.9 \%$ solution of $\mathrm{NaCl}$.

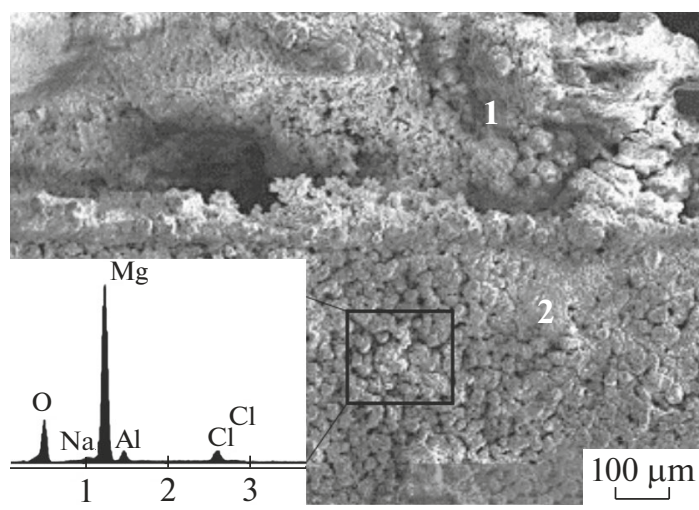

Fig. 5. Surface of MA5 magnesium alloy in the UFG state after corrosion for 25 days: (1) the region without NLI and (2) the region after NLI. The inset shows the results of the energy dispersive elemental analysis. alloy. It should be noted that a high rate of dissolution is observed at the initial stage of corrosion of a sample with the UFG structure, which leads to the loss of a significant weight of the sample (of about $11 \%$ of the weight during the first day), and, therefore, the shape of the sample can significantly change. Here, the high rate of corrosion can lead to the release of hydrogen in the form of bubbles, which is extremely dangerous for a living body [5]. This makes the execution of the surface modification of an alloy with the UFG structure an essential operation.

Continuous growth in the decline in the weight as a result of corrosion is observed in the coarse-grained sample (Fig. 3) at each time interval of the exposure of the alloy in the corrosive environment. Taking into account the fact that magnesium alloys possess low mechanical properties in the CG state, it can be concluded that their use as a material for the fabrication of medical devices is unreasonable even after NLI [23].

Corrosion tests of the irradiated samples in a $0.9 \%$ solution of $\mathrm{NaCl}$ (Fig. 4) showed that, despite the similarity of the parameters of the modified near-surface layer formed during NLI for the samples in the CG and UFG states, their corrosion resistance significantly differed. Thus, a sample with the UFG structure has no interval of fast dissolution which was observed in the unirradiated state at the initial stages of exposure, but a relatively higher level of corrosion resistance in comparison with the alloy with the CG structure is retained for the entire duration of the tests.

A laser-irradiated region (denoted by numeral 2) and a region without laser action (denoted by numeral 1 ) are clearly seen in the image of the surface of the magnesium alloy with the UFG structure subjected to corrosive action for 25 days (Fig. 5). The destruction of the surface of the alloy occurs and cracks and zones of corrosion dissolution significant in area are formed in region 1 as a result of corrosion. Region 2 has no such damage, and its relief is similar to that shown in Fig. 2. Here, the concentration of oxygen reaches $20 \%$ (inset in Fig. 5).

\section{CONCLUSIONS}

The treatment of the surface of the samples of MA5 magnesium alloy with pulsed nanosecond laser radiation makes it possible to form a modified near-surface layer free from intermetallic inclusions that are the major reason for the development of galvanic corrosion and thus increase the corrosion resistance of the alloy under study in a solution mimicking the physiological environment. The maximum effect is achieved under the condition of preliminary formation of an ultrafine-grained structure with the uniform distribution of small $(<1 \mu \mathrm{m})$ intermetallic particles in the bulk of the material of the blank. 


\section{ACKNOWLEDGMENTS}

We are grateful to Prof. Yu.R. Kolobov and Prof. V.P. Veiko for the participation in the discussion of the results and useful comments upon their analysis and to Prof. S.Ya. Betsofen for the participation in the development of the methods for the formation of ultrafine-grained structures in the studied magnesium alloys.

\section{FUNDING}

This work was financially supported by the Ministry of Education and Science of the Russian Federation as part of a state task for institutions of higher education, project code no. 3.3144.2017/4.6, and thematic map of the Institute of Problems of Chemical Physics, Russian Academy of Sciences, no. 0089-2019-0017 in part related to the testing of the procedure for the studies of the fine structure on a Quanta NOVA NanoSEM 450 microscope with field electron emission and a scanning transmission microscopy (STEM) detector.

\section{REFERENCES}

1. Magnesium Technology 2018, Orlov, D., Joshi, V., Solanki, K., and Neelameggham, N.R., Eds., New York: Springer-Verlag, 2018.

2. Kutnii, K.V., Nanostructured materials based on pure titanium and biosoluble magnesium alloy for surgical implants, Elektron. Svyaz, 2011, vol. 4, nos. 11-12, pp. 758-775.

3. Kainer, K.U., Magnesium: Alloys and Technology, New York: Willey, 2003.

4. Jingtao, C., Research of magnesium-based alloys for medical applications, Proc. 2nd Int. Conf. on Education Technology and Information System (ICETIS 2014), Jinan, China, Wang, L.G., Ed., Amsterdam: Atlantis, 2014, pp. 623-635.

5. Witte, F., Kaese, V., Haferkamp, H., Switzer, E., MeyerLindenberg, A., Wirth, C.J., and Windhagen, H., In vivo corrosion of four magnesium alloys and the associated bone response, Biomaterials, 2005, vol. 26, pp. 35573563.

6. Papirov, I.I., Shkuropatenko, V.A., Shokurov, V.S., and Pikapov, A.I., Materialy meditsinskikh stentov: Obzor (Medical Stents Materials: Overview), Kharkov: Khar'sk. Fiz.-Tekh. Inst., 2010.

7. Waksman, R., Erbel, R., Di Mario C., Bartunek, J., Bruyne, B., Eberli, F.R., Erne, P., Haude, M., Horrigan, M., Ilsley, C., Bose, D., Bonnier, H., Koolen, J., Luscher, T.F., and Weissman, N.J., Early- and longterm intravascular ultrasound and angiographic findings after bioabsorbable magnesium stent implantation in human coronary arteries, JACC: Cardiovasc. Interventions, 2009, vol. 2, no. 4, pp. 312-320.

8. Eggebrecht, H., Rodermann, J., Hunold, P., Schmermund, A., Bose, D., Haude, M., and Erbel, R., Novel magnetic resonance-compatible coronary stent: The absorbable magnesium-alloy stent, Circulation, 2005, vol. 112, pp. 303-304.

9. Zijian, L., Gu, X., Lou, S., Zheng, Y., and Zheng, Y.F., The development of binary $\mathrm{Mg}-\mathrm{Ca}$ alloys for use as biodegradable materials within bone, Biomaterials, 2008, vol. 29, pp. 1329-1344.

10. Gu, X.N., Xie, X.H., Li, N., Zheng, Y.F., and Qin, L., In vitro and in vivo studies on a $\mathrm{Mg}-$ Sr binary alloy system developed as a new kind of biodegradable metal, Acta Biomater., 2012, vol. 8, pp. 2360-2374.

11. Agarwal, S., Curtin, J., Duffy, D., and Jaiswal, S., Biodegradable magnesium alloys for orthopaedic applications: A review on corrosion, biocompatibility and surface modifications, Mater. Sci. Eng., C, 2016, vol. 68, pp. 948-963.

12. Kolobov, Yu.R., Technologies for the formation of medical implants based on titanium alloys with bioactive coatings, Nanotechnol. Russ., 2009, vol. 4, nos. 1112, pp. 758-775.

13. Bozhko, S.A., Kolobov, Yu.R., and Betsofen, S.Ya., Improvement of commercial $\mathrm{Mg}-\mathrm{Al}-\mathrm{Zn}-\mathrm{Mn}$ alloys by rolling, Proc. 2015 Int. Conf. on Structural, Mechanical and Material Engineering, Amsterdam: Atlantis, 2015. https://doi.org/10.2991/icsmme-15.2015.7

14. Kolobov, Yu.R., Golosov, E.V., Vershinina, T.N., Zhidkov, M.V., Ionin, A.A., Kudryashov, S.I., Makarov, S.V., Seleznev, L.V., Sinitsyn, D.V., and Ligachev, A.E. Structural transformation and residual stresses in surface layers of $\alpha+\beta$ titanium alloys nanotextured by femtosecond laser pulses, Appl. Phys. A: Mater. Sci. Process., 2015, vol. 119, no. 1, pp. 241-247.

15. Elkin, V.N., Malinskii, T.V., Mikolutskii, S.I., Khasaya, R.R., Khomich, Yu.V., and Yamshchikov, V.A., Effect of nanosecond laser irradiation on the surface structure of metal alloys, Fiz. Khim. Obrab. Mater., 2016, no. 6, pp. 5-12.

16. Ali, N., Bashir, S., and Chaudhry, U., Study of variation in surface morphology, chemical composition, crystallinity and hardness of laser irradiated silver in dry and wet environments, Opt. Laser Technol., 2017, vol. 92, pp. 173-181.

17. Li, X., Yuan, C., Yang, H., and Jiawen, L., Morphology and composition on $\mathrm{Al}$ surface irradiated by femtosecond laser pulses, Appl. Surf. Sci., 2010, vol. 256, pp. 4344-4349.

18. Ionin, A.A., Kudryashov, S.I., and Samokhin, A.A., Material surface ablation produced by ultrashort laser pulses, Phys. -Usp., 2017, vol. 60, pp. 149-160.

19. Betsofen, S.Ya., Bozhko, S.A., and Kolobov, Yu.R., RF Patent 2631574, Byull. Izobret., 2017, no. 27.

20. Ageev, E.I., Andreeva, Ya.M., Karlagina, Yu.Yu., Kolobov, Yu.R., Manokhin, S.S., Odintsova, G.V., and Veiko, V.P., Composition analysis of oxide films formed on titanium surface under pulsed laser action by method of chemical thermodynamics, Laser Phys., 2017, vol. 27, no. 4, p. 9.

21. Feng, H., Liu, S., Du, Y., Lei, T., Zeng, R., and Yuan, T., Effect of the second phases on corrosion behavior of the Mg-Al-Zn alloys, J. Alloys Compd., 2017, vol. 695, pp. 2330-2338.

22. Candan, S. and Candan, E., Comparative study on corrosion behaviors of $\mathrm{Mg}-\mathrm{Al}-\mathrm{Zn}$ alloys, Trans. Nonferrous Met. Soc. China, 2018, vol. 28, no. 4, pp. 642-650.

23. Manivasagam, G. and Suwas, S., Biodegradable $\mathrm{Mg}$ and $\mathrm{Mg}$ based alloys for biomedical implants, Mater. Sci. Technol., 2014, vol. 30, no. 5, pp. 515-520.

Translated by E. Boltukhina 